\title{
Improvement of Benin Patties and The Effects of Added Some Flour on Physicochemical Properties
}

\author{
Nasser Farid Geraldo \\ Researcher, Benin
}

\begin{abstract}
The residue of peanut oil extraction in Benin entered manufacture of snack locally called kluiklui. This snack was obtained after deep frying defatted dough of crushed seeds. This paper dealt with exploration and determination of patties physichochemical characteristics linked to crunchy descriptors and induced effects of adding some flour such as banana flour and glucomannan to defatted groundnut cake. Obtained results showed that, incorporating flour at reasonable percentages $5 \%$ (mass basis) improve crunchy quality and increase the indigestible fractions. However, recorded high value of remanant moisture 6.39 to $9.3 \%$ (dry basis) and fat 26.42 to $31.95 \%$ (dry basis), in the fried snack required further drying and improved oil cooking. The addition of flour increased the indigestible fraction in the kluiklui. Sample made with de-oiled peanut paste, glucomannan and type 3 resistant starch banana flour exhibited the highest indigestible fraction values attributed to the synergistic presence of the resistant starch, dietary fiber, protein and non-starch polysaccharides. The same sample exhibited lower fracturability and higher hardness than others. Results of the sensory quality evaluation showed that incorporation of flour into the kluiklui showed no significant differences in liking scores in terms of appearance, aroma, taste and overall acceptability; whereas, the texture and the color scores were significantly different than the control kluiklui. Although the use of flour does not arouse consumer's acceptability. Flour-enriched kluiklui was significantly higher in all the sensory attributes considered. Overall, the flour-enriched kluiklui produced, was favorably and acceptable, thus showing prospects for industrial application of the flourenriched kluiklui. In addition, the low resistance to rupture of flour-enriched kluiklui has confirmed their crispy behavior compared to those resulting from defatted pure cake. The resistance of the texture indicated that the production conditions were unfavorable for handling and transport and Overall, banana flour and glucomannan can be successfully incorporated into kluiklui to enrich its values contents.
\end{abstract}

Keywords: Kluiklui, flour-enriched kluiklui, indigestible fractions, glucomannan, banana flour 